\title{
Necrològica
}

\section{Fills de la perplexitat. Obituari per Javier Muguerza}

El 10 d'abril d'enguany ens va deixar Javier Muguerza (1936-2019), que va ser professor del Departament de Filosofia de la Universitat Autònoma els anys 1976-1978. Per als qui aleshores n'érem estudiants va ser com un brillantíssim meteor que va passar per les nostres vides en els darrers anys de formació en l'aleshores jove Universitat Autònoma de Barcelona. Muguerza venia de La Laguna i va fer parada a la nostra institució docent abans de marxar cap a Madrid, a la UNED, on va estar la resta de la seva vida, on fundà l'Instituto de Filosofia del CSIC i la revista Isegoría. Aquell filòsof del desacord i la perplexitat, que malgrat tot va ser un defensor aferrissat de la racionalitat, de l'ètica i de la democràcia, es va convertir inesperadament en un far intel.lectual i moral per a alguns de nosaltres. Un far la lucidesa i les ombres del qual es projecten encara amb intensitat sobre el nostre treball en el present. Javier Muguerza no va ser un racionalista ad usum, ni filosòficament ni en la seva conducta de vida. Humà — de vegades, massa humà-, va contribuir com pocs a difondre la filosofia analítica a Espanya, alhora que eren evidents les seves simpaties per la teoria crítica frankfurtiana. Aquesta posició l'acostà indefectiblement a un dels grans pensadors del darrer mig segle, Jürgen Habermas, que també es trobà en aquesta posició de l'humanisme frankfurtià empeltat d'anàlisi filosòfica. De Habermas, tanmateix, el va separar sempre la mateixa diferència que aquest mantingué amb Adorno: que la tasca de la vertadera filosofia crítica no està en la cerca dels consensos i dels acords sobre principis, sinó a treballar sobre els dissensos i els desacords, no en la construcció de grans teories i propostes sistemàtiques, sinó a mostrar com a falses les pretensions absolutistes d'aquestes. Enfront de les situacions ideals de diàleg, sempre va defensar el diàleg real. Però això no el va acostar cap a les posicions postmodernes, els pensaments dèbils ni els relativismes o els escepticismes de saló. Mentre era professor del nostre departament, Muguerza va publicar el seu primer llibre, La razón sin esperanza (Taurus, 1977), que s'obria amb una citació d'Ernst Bloch: "La razón no puede prosperar sin esperanza, ni la esperanza sin razón", però que acabava apostant per la raó, amb esperança, sense esperança, i fins i tot contra l'esperança. Llegint un article recent d'Eliane Brum sobre Greta Thunberg i la primera generació sense esperança (<https://elpais. com/internacional/2019/06/06/actualidad/1559839530_174712.html>), 
podem constatar l'actualitat dels plantejaments de Muguerza de fa més de quaranta anys. Fills de la perplexitat, no podem deixar de considerar-nos membres de la wittgeinsteiniana família d'aquells que creiem en la raó sense esperança.

Jordi Riba Gerard Vilar

Universitat Autònoma de Barcelona 